\title{
On the utility of the molecular oxygen dayglow emissions as proxies for middle atmospheric ozone
}

\author{
Martin G. Mlynczak \\ NASA Langley Research Center, Hampton, Virginia \\ Daphne S. Olander ${ }^{1}$ \\ Science Applications International Corporation, Hampton, Virginia
}

\begin{abstract}
The molecular oxygen dayglow emissions, $\mathrm{O}_{2}\left(\mathrm{a}^{1} \Delta_{\mathrm{g}} \rightarrow \mathrm{X}^{3} \Sigma_{\mathrm{g}}\right)$ at $1.27 \mu \mathrm{m}$ and $\mathrm{O}_{2}\left(\mathrm{~b}^{1} \Sigma_{\mathrm{g}} \rightarrow \mathrm{X}^{3} \Sigma_{\mathrm{g}}\right)$ at $762 \mathrm{~nm}$, arise in part from processes related to the Hartley band photolysis of ozone. It is therefore possible to derive daytime ozone concentrations from measurements of the volume emission rate of either dayglow. The accuracy to which the ozone concentration can be inferred depends on the accuracy to which numerous kinetic and spectroscopic rate constants are known, including rates which describe the excitation of molecular oxygen by processes that are not related to the ozone concentration. We find that several key rate constants must be known to better than $7 \%$ accuracy in order to achieve an inferred ozone concentration accurate to $15 \%$ from measurements of either dayglow. Currently, accuracies for various parameters typically range from $5 \%$ to $100 \%$.
\end{abstract}

\section{Introduction}

Understanding the distribution of ozone in the terrestrial mesosphere and lower thermosphere is a fundamental problem in atmospheric science. A complete description of the thermal structure and photochemistry of the region is not fully possible unless the ozone abundance is well characterized. To understand the distribution of ozone on a global basis requires remote detection from space-based observing platforms. The ozone concentration may be determined directly by measurements of cmission from ozone itself and indirectly from measurements of emission from species that are produced as a result of ozone photolysis. Specifically, the two lowest-lying electronically excited states of molecular oxygen, $\mathrm{O}_{2}\left(\mathrm{a}^{1} \Delta_{\mathrm{g}}\right)$ and $\mathrm{O}_{2}\left(\mathrm{~b}^{1} \Sigma_{\mathrm{g}}\right)$ (hereafter $\mathrm{O}_{2}\left({ }^{\prime} \Delta\right)$ and $\left.\mathrm{O}_{2}\left({ }^{\prime} \Sigma\right)\right)$ are created, in part, directly and indirectly as a result of photolysis in the Hartley band of ozone. Radiative cmission from these two states thus provides an indirect measure of the ozone abundance. Observation of the $\mathrm{O}_{2}\left({ }^{1} \Delta\right)$ airglow at $1.27 \mu \mathrm{m}$ has been used to infer the ozonc concentration by the Solar Mesosphere Explorer (SME) experiment [Thomas et al., 1984], and the $\mathrm{O}_{2}\left({ }^{l} \Sigma\right)$ airglow at 762 $\mathrm{nm}$ as measured by the High-Resolution Doppler Imager (HRDI) on the Upper Atmosphere Research Satellite (UARS) is currently being considered as an ozone proxy [Yee et al., 1993]. The $\mathrm{O}_{2}\left({ }^{\mathrm{l}} \Delta\right)$ airglow will also be observed by the Sounding of the Atmosphere using Broadband Emission Radiometry (SABER)

\footnotetext{
'Now at NOAA Science Center, Washington, DC 20233.
}

This paper is not subject to U.S. copyright. Published in 1995 by the American Geophysical Union.

Paper number 95GL01321 experiment [Russell et al., 1994] selected for NASA's Thermosphere-lonosphere-Mesosphere Energetics and Dynamics (TIMED) mission.

The purpose of this letter is to identify the key kinetic and spectroscopic rates which relate the measured airglow intensities to the ozone concentration and to define quantitatively the accuracy to which these rates must be known in order to achieve an ozone concentration with an uncertainty of $15 \%$, in order to guide new laboratory measurements. This study is similar to that of Harries [1982] who determined the rate constant accuracies required to achieve a good inference of hard-to-measure chemical species given measurements of related species and the photochemical relations between the species. We will show, using an approach similar to Harries', that significant improvements in the accuracy of the rate constants which describe collisional cnergy transfer, radiative absorption, and spontaneous emission in the coupled oxygen-ozone dayglow system are needed before ozone can be confidently inferred to an accuracy of $15 \%$ or better.

\section{Methodology}

The oxygen dayglow model used in this study is described by Mlynczak et al. [1993] and the relevant processes are listed in Table 1. The reader is referred to Figure 1 of Mlynczak et al. [1993] for a schematic illustration of the processes which generate molecular oxygen airglow. There are a total of 26 parameters which must be specified in order to calculate the $\mathrm{O}_{2}\left({ }^{1} \Delta\right)$ or $\mathrm{O}_{2}\left({ }^{1} \Sigma\right)$ volume emission rate. However, as will be shown, accurate inference of ozone from either dayglow requires good knowledge of 6 to 8 parameters.

To calculate the uncertainty in ozone due to uncertainties in the parameters, we evaluate the following expression for the standard deviation (variance) of the inferred ozone

$$
S^{2}=\sum_{i}\left[\frac{1}{O_{3}} \frac{\partial O_{3}}{\partial x_{i}} s_{i}\right]^{2}
$$

where $S^{2}$ is the total variance (ultimately expressed as a percentage of the true ozone concentration), $\mathrm{O}_{3}$ is the true ozone concentration, $\partial \mathrm{O}_{3} / \partial \mathrm{x}_{\mathrm{i}}$ is the derivative of the ozone concentration with respect to kinetic or spectroscopic parameter $x_{i}$, and $s_{i}$ is the uncertainty in parameter $x_{i}$. It is assumed that the individual parameters $x_{i}$ are uncorrelated such that the total uncertainty $S\left(S=\left(S^{2}\right)^{1 / 2}\right)$ in the inferred ozone concentration is given by the root-sum-square of the individual uncertainties. as in Harries [1982]. The terms composing the sum on the right hand side of Eq. 1 are evaluated numerically by first calculating the 
Table 1. Kinetic and spectroscopic processes in the molecular oxygen airglow.

\begin{tabular}{lll}
\hline \multicolumn{1}{c}{ Process } & Rate Symbol & \multicolumn{1}{c}{ Description } \\
\hline $\mathrm{O}_{3}+\mathrm{hv} \rightarrow \mathrm{O}_{2}\left({ }^{1} \Delta\right)+\mathrm{O}\left({ }^{1} \mathrm{D}\right)$ & $\phi_{\mathrm{a}} \mathrm{J}_{\mathrm{a}}$ & Hartley photolysis \\
$\mathrm{O}_{2}+\mathrm{hv} \rightarrow \mathrm{O}\left({ }^{3} \mathrm{P}\right)+\mathrm{O}\left({ }^{1} \mathrm{D}\right)$ & $\phi_{\mathrm{L}} \mathrm{L}$ & Ly- $\alpha$ photolysis \\
$\mathrm{O}_{2}+\mathrm{hv} \rightarrow \mathrm{O}\left({ }^{3} \mathrm{P}\right)+\mathrm{O}\left({ }^{1} \mathrm{D}\right)$ & $\mathrm{J}_{\mathrm{S}}$ & Schum.-Run. photol. \\
$\mathrm{O}_{2}+\mathrm{hv}(762 \mathrm{~nm}) \rightarrow \mathrm{O}_{2}\left({ }^{1} \Sigma\right)$ & $\mathrm{J}_{1} \mathrm{~S}$ & Solar absorption \\
$\mathrm{O}\left({ }^{1} \mathrm{D}\right)+\mathrm{N}_{2} \rightarrow \mathrm{O}\left({ }^{3} \mathrm{P}\right)+\mathrm{N}_{2}$ & $\mathrm{k}_{\mathrm{c}}$ & Collisional quench. \\
$\mathrm{O}\left({ }^{1} \mathrm{D}\right)+\mathrm{O}_{2} \rightarrow \mathrm{O}_{2}\left({ }^{1} \Sigma\right)+\mathrm{O}\left({ }^{3} \mathrm{P}\right)$ & $\phi_{\mathrm{d}} \mathrm{k}_{\mathrm{d}}$ & Collisional quench. \\
$\mathrm{O}\left({ }^{1} \mathrm{D}\right)+\mathrm{O}_{2} \rightarrow \mathrm{O}_{2}+\mathrm{O}\left({ }^{3} \mathrm{P}\right)$ & $\left(1-\phi_{\mathrm{d}}\right) \mathrm{k}_{\mathrm{d}}$ & \\
$\mathrm{O}_{2}\left({ }^{1} \Delta\right)+\mathrm{O}_{2} \rightarrow \mathrm{O}_{2}+\mathrm{O}_{2}$ & $\mathrm{k}_{\mathrm{i}}$ & Collisional quench. \\
$\mathrm{O}_{2}\left({ }^{1} \Delta\right)+\mathrm{N}_{2} \rightarrow \mathrm{O}_{2}+\mathrm{N}_{2}$ & $\mathrm{k}_{\mathrm{j}}$ & Collisional quench. \\
$\mathrm{O}_{2}\left({ }^{1} \Delta\right)+\mathrm{O} \rightarrow \mathrm{O}_{2}+\mathrm{O}$ & $\mathrm{k}_{1}$ & Collisional quench. \\
$\mathrm{O}_{2}\left({ }^{1} \Delta\right) \rightarrow \mathrm{O}_{2}+\mathrm{hv}(1.27 \mu \mathrm{m})$ & $\mathrm{A}_{\mathrm{H}}$ & Spontan. emission \\
$\mathrm{O}_{2}\left({ }^{1} \Sigma\right)+\mathrm{M} \rightarrow \mathrm{O}_{2}\left({ }^{1} \Delta\right)+\mathrm{M}$ & $\phi_{\mathrm{c}} \mathrm{k}_{\mathrm{f}}$ & Collisional quench. \\
$\mathrm{O}_{2}\left({ }^{1} \Sigma\right)+\mathrm{M} \rightarrow \mathrm{O}_{2}\left({ }^{3} \Sigma\right)+\mathrm{M}$ & $\left(1-\phi_{\mathrm{e}} \mathrm{k}_{\mathrm{f}}\right)$ & \\
$\mathrm{O}_{2}\left({ }^{1} \Sigma\right) \rightarrow \mathrm{O}_{2}+\mathrm{h} v(762 \mathrm{~nm})$ & $\mathrm{A}_{\mathrm{K}}$ & Spontan. emission
\end{tabular}

molecular oxygen volume emission rate, then perturbing an individual parameter (such as a quenching rate), followed by deriving the ozone concentration using the calculated volume emission rate and the perturbed value of the specified parameter. This is done for each parameter as a function of height between $10 \mathrm{hPa}$ (approximately $30 \mathrm{~km}$ ) to $10^{-4} \mathrm{hPa}$ (approximately 110 $\mathrm{km}$ ). The model atmosphere is taken from Garcia and Solomon $[1983,1985]$ at equinox and low latitudes.

\section{Results}

As discussed by Mlynczak et al. 119931. $\mathrm{O}_{2}\left({ }^{\prime} \Delta\right)$ can be generated directly upon photolysis of ozone in the Hartley band and indirectly by quenching of the $\mathrm{O}_{2}\left({ }^{1} \Sigma\right)$ statc. The $\mathrm{O}_{2}\left({ }^{1} \Sigma\right)$ state can be generated in two different ways including direct excitation by sunlight at $762 \mathrm{~nm}$ and by energy transfer from $\mathrm{O}\left({ }^{1} \mathrm{D}\right)$. There are a total of five sources of $\mathrm{O}_{2}\left({ }^{1} \Delta\right)$ and four sources of $\mathrm{O}_{2}\left({ }^{1} \Sigma\right)$ considered in this work. Shown in Figures 1 and 2 are the relative contribution of each source to the total $\mathrm{O}_{2}\left({ }^{\prime} \Delta\right)$ and $\mathrm{O}_{2}\left({ }^{l} \Sigma\right)$ abundances, respectively. The sources corresponding to each numbered curve are described in the figure captions.

We apply the methodology described above to the problem of inferring the ozone concentration from measured oxygen airglow emission intensities initially assuming the following uncertaintics in each parameter: $5 \%$ in $A_{K} ; 6 \%$ in $\phi_{i b}, 10 \%$ in $\phi_{c} ; 15 \%$ in $J_{1 S}$, $\mathbf{J}_{\mathrm{a}}$, and $A_{H} ; 20 \%$ in $\mathbf{J}_{S}, J_{L}, k_{c}, k_{d}, k_{f}, k_{j}, k_{j}$, and $k_{l} ; 30 \%$ in $\phi_{d}$; and $\phi_{1}$, was varied between 0.44 and 1.0. Species densities $\left(\mathrm{N}_{2}\right.$, $\mathrm{O}_{2}, \mathrm{CO}_{2}, \mathrm{O}_{3}$, and $\mathrm{O}$ ) and temperature were held fixed in both forward and inverse calculations. Varying the quenching rates of $\mathrm{O}_{2}\left({ }^{\prime} \mathrm{\Sigma}\right)$ by $\mathrm{O}_{2}, \mathrm{CO}_{2}, \mathrm{O}_{3}$, and $\mathrm{O}$ by $20 \%$ resulted in no significant uncertainty in retricved ozone.

Shown in Table 2 are the results of the study for inferring azone from measurements of $\mathrm{O}_{2}\left({ }^{1} \Delta\right)$ emission. In each column is the percentage change (as a function of altitude) in the inferred ozone concentration due to the indicated change in the parameter listed at the top of each column. The six parameters listed $\left(\mathrm{J}_{1 \mathrm{~S}}\right.$, $J_{\mathrm{a}}, A_{\mathrm{H}}, \phi_{\mathrm{d}}, \phi_{\mathrm{e}}$, and $\mathrm{k}_{\mathrm{i}}$ ) account for nearly all of the variance in the retricved ozone. The column labeled RSS is the root-sum square of the error due to the uncertainties in all parameters. In this column we see that at the indicated levels of parameter uncertainty the inferred ozone is accurate from $25 \%$ to $30 \%$ below $80 \mathrm{~km}$ and from $17 \%$ to $20 \%$ between 80 and $90 \mathrm{~km}$. Above $90 \mathrm{~km}$ the uncertainty rapidly increases because ozone provides only a small fraction of the $\mathrm{O}_{2}\left({ }^{1} \Delta\right)$ abundance. The stated goal of $15 \%$ uncertainty is not achieved with uncertainties of $10 \%$ to $30 \%$ in the six key parameters listed in Table 2 . The total systematic error presented here for ozone concentrations derived from measurements of $\mathrm{O}_{2}\left({ }^{l} \Delta\right)$ emission are consistent with those presented for the SME experiment by Thomas et al. [1984].

An important question is by how much should the uncertainties be reduced in order to bring the total uncertainty in retrieved ozone below $15 \%$. For simplicity, we require that each of the six parameters he known to the same accuracy and then determine the minimum uncertainty required to bring the overall uncertainty in the inferred ozone below $15 \%$ over most of the altitude range.

The column labeled RSS' in Table 2 is the total uncertainty in inferred ozone calculated using a $7 \%$ uncertainty in the six key parameters identified above. The uncertainties in all other parameters are unchanged. Below $\sim 92 \mathrm{~km}$ the accuracy is better than $15 \%$ except near $75 \mathrm{~km}$ where the uncertainty approaches 20\%. As shown in Figure 1, above $92 \mathrm{~km}$ and near $75 \mathrm{~km}$, ozone is responsible for less than l.inf of the $\mathrm{O}_{2}\left({ }^{1} \Delta\right)$, and the inferred ozone at these altitudes is very sensitive to relatively small uncertainties in the airglow model parameters. From this analysis we conclude that the six key rate constants defined above need to be known to an accuracy of about $7 \%$ or better to allow ozone to be inferred from measurements of the $\mathrm{O}_{2}\left({ }^{1} \Delta\right)$ airglow to an accuracy of $15 \%$. Of the six parameters, $J_{1}$ s and $J_{a}$ are not laboratory measured rates but are calculated using solar intensity. absorption cross section. and atmospheric composition data. As such, future laboratory research should concentrate on improvements in parameters $A_{H}, \phi_{d}, \phi_{e}$, and $k_{i}$. Priority should

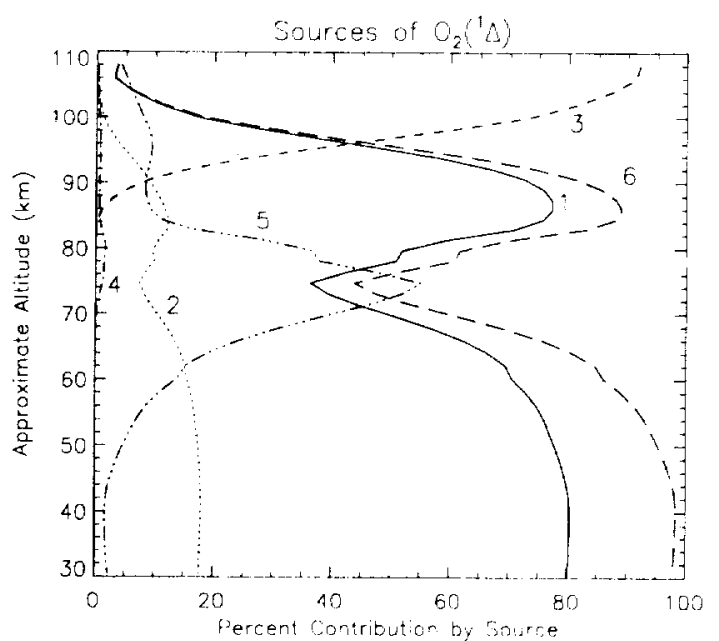

Figure 1. Relative magnitude of sources of $\mathrm{O}_{2}\left({ }^{1} \Delta\right)$. Curve 1 is production directly from ozone photolysis. Curves 2 through 5 represent production of $\mathrm{O}_{2}\left({ }^{1} \Delta\right)$ from collisional quenching of $\mathrm{O}_{2}\left({ }^{1} \Sigma\right)$. Curve 2 is production indirectly from $\mathrm{O}\left({ }^{1} \mathrm{D}\right)$ generated by ozone photolysis, Curve 3 is production indirectly from $O\left({ }^{1} \mathrm{D}\right)$ generated by $\mathrm{O}_{2}$ photolysis in the Schumann-Runge continuum, Curve 4 is production indirectly from $\mathrm{O}_{2}$ photolysis at Ly- $\alpha$. wavelengths, and Curve 5 is from production of $\mathrm{O}_{2}\left({ }^{1} \Sigma\right)$ by absorption of sunlight at $762 \mathrm{~nm}$. Curve 6 is the sum of Curves 1 and 2 which represents the total ozone-related production of $\mathrm{O}_{2}\left({ }^{1} \Delta\right)$. 


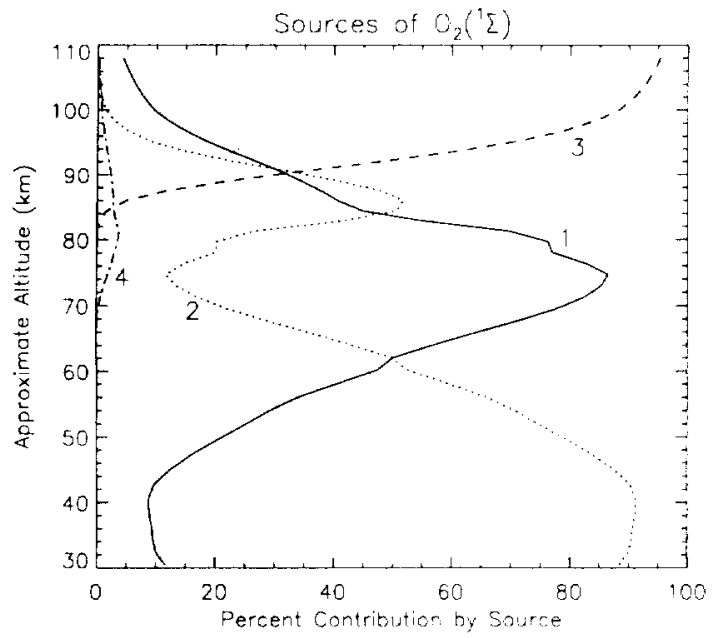

Figure 2. Relative magnitudes of sources of $\mathrm{O}_{2}\left({ }^{1} \Sigma\right)$. Curve 1 is production duc to resonant absorption of sunlight at $762 \mathrm{~nm}$, Curve 2 production due to energy transfer from $O\left({ }^{1} D\right)$ generated directly from ozone photolysis, Curve 3 is production due to $O\left({ }^{1} D\right)$ generated by photolysis of $\mathrm{O}_{2}$ in the Schumann-Runge continuum, and Curve 4 is production due to $O\left({ }^{1} D\right)$ generated by photolysis of $\mathrm{O}_{2}$ at $\mathrm{Ly}-\alpha$ wavelengths.

be placed upon $A_{H}$ and $k_{i}$ as the root-sum-square of the errors due to uncertainty in $\phi_{\mathrm{d}}$ and $\phi_{\mathrm{C}}$ below $\sim 92 \mathrm{~km}$ is small $(6 \%-7 \%)$ except near $75 \mathrm{~km}$.

In a similar manner the uncertainty in inferred ozone from measurements of the $\mathrm{O}_{2}\left({ }^{l} \Sigma\right)$ airglow was determined. The results are listed in Table 3 in the same fashion as Table 2. Initial parameter uncertainties are as given above for the $\mathrm{O}_{2}\left({ }^{1} \Delta\right)$ airglow. We find that eight parameters $\left(J_{1 S}, J_{a}, A_{K}, \phi_{d}, \phi_{L}, k_{c}, k_{d}\right.$, and $k_{f}$ ) contribute most to the variance, and at the stated initial levels of parameter uncertainty the accuracy in inferred ozone is no better than $50 \%$ (column RSS) at all altitudes. The uncertainty is very large near $75 \mathrm{~km}$ and above $90 \mathrm{~km}$ because ozone is responsible for less than half of the $\mathrm{O}_{2}\left({ }^{1} \Sigma\right)$ at those altitudes (as shown in Figure 2).

Because of the large uncertainty in $\mathrm{O}_{2}\left({ }^{1} \Sigma\right)$-inferred ozone at all altitudes, we specified a $5 \%$ uncertainty on all parameters and then recalculated the uncertainty in inferred ozone, which is given in the column labeled RSS' in Table 3. The goal of $15 \%$ is achicved only below $60 \mathrm{~km}$ and near $85 \mathrm{~km}$ where, as shown in Figure 2, ozone is responsible for more than half of the $\mathrm{O}_{2}\left({ }^{1} \Sigma\right)$. Between 60 and $85 \mathrm{~km}$, processes involving ozone generate only $10 \%$ to $50 \%$ of the $\mathrm{O}_{2}\left({ }^{1} \Sigma\right)$, and the inferred ozone is therefore extremely sensitive to parameter uncertainty.

From this analysis, it appears that the $\mathrm{O}_{2}\left({ }^{1} \Sigma\right)$ dayglow may provide a good proxy for ozone in the upper stratosphere and lower mesosphere (30 to $60 \mathrm{~km}$ ) and also near $85 \mathrm{~km}$. However, as with the $\mathrm{O}_{2}\left({ }^{l} \Delta\right)$ airglow, there needs to be significant improvement in the knowledge of kinetic and spectroscopic rates. Specifically, below $60 \mathrm{~km}$ there are six parameters whose uncertainty is responsible for virtually all of the uncertainty in the inferred ozone, $\mathbf{J}_{\mathrm{i}}, \mathbf{k}_{\mathrm{c}}, \mathrm{k}_{\mathrm{d}}, \phi_{\mathrm{d}}, \mathrm{k}_{\mathrm{f}}$, and $\mathrm{A}_{\mathrm{K}}$. Of these six parameters, $J_{a}$ and $\phi_{d}$ are also indicated for improvement above in the discussion of the $\mathrm{O}_{2}\left({ }^{1} \Delta\right)$ airglow. It is unlikely that the accuracy of $A_{K}(5 \%)$ will be improved, so future laboratory research should focus on improving $k_{c}, k_{d}$, and $k_{f}$ to an accuracy of $\sim 5 \%$.
There are other sources of systematic error to be considered other than rate constant uncertainty. These may include instrument calibration errors, radiative transfer errors, line-of sight $\mathrm{O}_{2}$ abundance errors, instrument pointing, and temperaturepressure registration. Typical uncertainties $(<3 \mathrm{~K})$ in simultaneously measured temperatures will not cause additional significant error in the rate constants provided the temperature dependence is known over the range of expected temperatures $(140 \mathrm{~K}$ to $270 \mathrm{~K})$. Of these additional error mechanisms, instrument calibration can be a serious error component of upper mesospheric and lower thermospheric ozone inferred from measurements of $\mathrm{O}_{2}\left({ }^{1} \Sigma\right)$ even if the kinetics are well known. Shown in Tables 2 and 3 in the columns labeled $\mathrm{Cal}$ is the error in inferred ozone duc to a $5 \%$ uncertainty in the absolute calibration of an instrument which determines the $\mathrm{O}_{2}\left({ }^{1} \Delta\right)$ or $\mathrm{O}_{2}\left({ }^{1} \Sigma\right)$ volume emission rate. Calibration errors result in large uncertainties $(10 \%$ to $100 \%)$ in $\mathrm{O}_{2}\left({ }^{1} \Sigma\right)$-inferred ozone above 60 $\mathrm{km}$ because ozone is responsible for a small portion of the total $\mathrm{O}_{2}\left({ }^{l} \Sigma\right)$ abundance.

Finally, we have also considered the impact that simultaneous measurements of both oxygen airglows would have on the uncertainty in the derived ozone concentration. $\mathrm{O}_{2}\left({ }^{\prime} \Sigma\right)$-derived ozone is independent of the $\mathrm{O}_{2}\left({ }^{1} \Delta\right)$ concentration, but $\mathrm{O}_{2}\left({ }^{1} \Delta\right)$ derived ozone is not. Therefore, simultaneous measurements of both airglows could possibly reduce the uncertainty only in $\mathrm{O}_{2}\left({ }^{1} \Delta\right)$-derived ozone. However, our studies show that if the $\mathrm{O}_{2}\left({ }^{\prime} \Sigma\right)$ concentration is known (by measurement or calculation) to $10 \%$ accuracy there will be little improvement in the uncertainty in ozone concentrations derived from measurements of the $\mathrm{O}_{2}\left({ }^{1} \Delta\right)$ airglow. This result is a consequence of the fact that the bulk of the uncertainty in $\mathrm{O}_{2}\left({ }^{1} \Delta\right)$-derived ozone is from parameters such as $J_{a}, A_{H}$, and $k_{i}$ which relate the $\mathrm{O}_{2}\left({ }^{1} \Delta\right)$ emission rate to the ozone concentration and from the fact that (below $\sim 92 \mathrm{~km}$ ) the bulk of the $\mathrm{O}_{2}\left({ }^{1} \Delta\right)$ is generated from ozone photolysis.

Table 2. Errors in retrieved ozone due to errors in kinetic and spectroscopic rate parameters associated with the $\mathrm{O}_{2}\left({ }^{1} \Delta\right)$ airglow at $1.27 \mu \mathrm{m}$. See text for description.

\begin{tabular}{|c|c|c|c|c|c|c|c|c|c|}
\hline $\begin{array}{l}\text { Param. } \\
\text { Error }\end{array}$ & $\begin{array}{r}\mathrm{J}_{1 \mathrm{~S}} \\
1.15\end{array}$ & $\begin{array}{c}\mathrm{J}_{\mathrm{a}} \\
1.15\end{array}$ & $\begin{array}{r}\mathrm{A}_{\mathrm{H}} \\
1.15\end{array}$ & $\begin{array}{r}\phi_{\mathrm{d}} \\
1.3\end{array}$ & $\begin{array}{l}\phi_{\mathrm{e}} \\
1.1\end{array}$ & $\begin{array}{r}\mathrm{k}_{\mathrm{i}} \\
1.2\end{array}$ & RSS & RSS' $^{\prime}$ & $\begin{array}{l}\text { Cal. } \\
1.05\end{array}$ \\
\hline \multicolumn{10}{|c|}{$\underline{\mathrm{Z}(\mathrm{km})}$} \\
\hline 100.0 & -6.5 & -13.0 & -12.3 & 138.2 & 49.8 & -0.5 & 236.3 & 190.3 & 29.4 \\
\hline 96.9 & -3.5 & -13.0 & -6.3 & 45.9 & 17.4 & -0.4 & 74.2 & 56.5 & 13.2 \\
\hline 93.7 & -2.1 & -13.0 & -4.1 & 17.1 & 7.0 & -0.5 & 30.6 & 22.2 & 8.0 \\
\hline 90.6 & -1.6 & -13.0 & -3.1 & 8.1 & 3.7 & -0.7 & 20.6 & 14.9 & 6.3 \\
\hline 87.5 & -1.5 & -13.0 & -2.6 & 5.3 & 2.7 & -1.2 & 17.8 & 12.3 & 5.7 \\
\hline 84.4 & -1.9 & -13.0 & -2.4 & 4.8 & 2.8 & -2.1 & 16.8 & 10.8 & 5.7 \\
\hline 81.3 & -6.0 & -13.0 & -3.4 & 5.5 & 5.9 & -4.6 & 19.2 & 11.8 & 7.1 \\
\hline 78.1 & -9.3 & -13.0 & -5.8 & 5.9 & 8.2 & -8.5 & 23.1 & 13.5 & 8.2 \\
\hline 74.7 & -18.9 & -13.0 & -11.8 & 6.3 & 14.8 & -17.5 & 36.2 & 19.5 & 11.5 \\
\hline 71.3 & -12.7 & -13.0 & -13.0 & 5.8 & 10.5 & -19.3 & 32.7 & 16.6 & 9.3 \\
\hline 67.8 & -6.6 & -13.0 & -12.7 & 5.6 & 6.3 & -18.9 & 29.2 & 14.4 & 7.2 \\
\hline 64.1 & -3.6 & -13.0 & -12.7 & 5.7 & 4.2 & -18.9 & 28.3 & 13.8 & 6.2 \\
\hline 60.2 & -2.4 & -13.0 & -13.1 & 5.7 & 3.5 & -19.6 & 28.8 & 13.9 & 5.8 \\
\hline 56.1 & -1.4 & -13.0 & -13.1 & 5.8 & 2.8 & -19.6 & 28.7 & 13.8 & 5.5 \\
\hline 51.7 & -0.9 & -13.0 & -13.2 & 5.8 & 2.5 & -19.7 & 28.7 & 13.8 & 5.3 \\
\hline 47.3 & -0.5 & -13.0 & -13.1 & 5.8 & 2.2 & -19.7 & 28.6 & 13.8 & 5.2 \\
\hline 42.8 & -0.3 & -13.0 & -13.1 & 5.8 & 2.1 & -19.6 & 28.6 & 13.7 & 5.1 \\
\hline 38.5 & -0.3 & -13.0 & -13.2 & 5.8 & 2.0 & -19.7 & 28.6 & 13.7 & 5.1 \\
\hline 34.4 & -0.3 & -13.0 & -13.2 & 5.8 & 2.0 & -19.8 & 28.7 & 13.8 & 5.1 \\
\hline 30.5 & -0.4 & -13.0 & -13.3 & 5.7 & 2.1 & -19.9 & 28.8 & 13.8 & 5.1 \\
\hline
\end{tabular}


Table 3. Errors in retrieved ozone due to errors in kinetic and spectroscopic rates associated with the $\mathrm{O}_{2}\left({ }^{\mathrm{l} \Sigma}\right)$ airglow at $762 \mathrm{~nm}$. See text for description.

\begin{tabular}{|c|c|c|c|c|c|c|c|c|c|c|c|}
\hline $\begin{array}{l}\text { Parameter: } \\
\text { Uncertainty: }\end{array}$ & $\begin{array}{r}J_{1 S} \\
1.15\end{array}$ & $\begin{array}{r}\mathbf{J}_{\mathbf{a}} \\
1.15\end{array}$ & $\begin{array}{r}A_{K} \\
1.05\end{array}$ & $\begin{array}{c}\phi_{\mathrm{d}} \\
1.3\end{array}$ & $\begin{array}{r}\phi_{\mathrm{L}} \\
2.24\end{array}$ & $\begin{array}{l}\mathbf{k}_{\mathrm{c}} \\
1.2\end{array}$ & $\begin{array}{r}\mathrm{k}_{\mathrm{d}} \\
1.20\end{array}$ & $\begin{array}{r}k_{\mathrm{f}} \\
1.20\end{array}$ & RSS & $\mathrm{RSS}^{\prime}$ & $\begin{array}{l}\text { Cal. } \\
1.05\end{array}$ \\
\hline \multicolumn{12}{|l|}{$\mathrm{Z}(\mathrm{km})$} \\
\hline$\overline{100.0}$ & -101.0 & -13.0 & -129.0 & 3012.0 & -61.0 & -1056.0 & 1320.0 & 139.0 & 3811.2 & 954.8 & 387.5 \\
\hline 96.9 & -44.0 & -13.0 & -44.0 & 809.0 & -27.0 & -280.0 & 350.0 & 65.0 & 1017.2 & 250.0 & 109.7 \\
\hline 93.7 & -22.0 & -13.0 & -17.0 & 252.0 & -14.0 & -86.0 & 108.0 & 35.0 & 312.5 & 72.6 & 37.3 \\
\hline 90.6 & -14.0 & -13.0 & -9.0 & 102.0 & -8.0 & -35.0 & 43.0 & 24.0 & 124.7 & 25.9 & 16.9 \\
\hline 87.5 & -11.0 & -13.0 & -6.0 & 58.0 & -7.0 & -20.0 & 25.0 & 22.0 & 73.1 & 14.9 & 10.9 \\
\hline 84.4 & -13.0 & -13.0 & -7.0 & 47.0 & -7.0 & -16.0 & 20.0 & 25.0 & 62.9 & 14.1 & 10.0 \\
\hline 81.3 & -39.0 & -13.0 & -15.0 & 48.0 & -18.0 & -16.0 & 20.0 & 57.0 & 92.2 & 26.5 & 18.9 \\
\hline 78.1 & -57.0 & -13.0 & -21.0 & 49.0 & -20.0 & -16.0 & 20.0 & 81.0 & 118.2 & 36.2 & 24.9 \\
\hline 74.7 & -111.0 & -13.0 & -38.0 & 50.0 & -23.0 & -17.0 & 21.0 & 147.0 & 198.8 & 65.0 & 43.1 \\
\hline 71.3 & -73.0 & -13.0 & -27.0 & 44.0 & -6.0 & -15.0 & 18.0 & 104.0 & 140.2 & 45.5 & 29.6 \\
\hline 67.8 & -37.0 & -13.0 & -16.0 & 42.0 & 0.0 & -14.0 & 17.0 & 62.0 & 89.1 & 26.6 & 17.6 \\
\hline 64.1 & -19.0 & -13.0 & -10.0 & 42.0 & 0.0 & -14.0 & 17.0 & 41.0 & 67.8 & 17.9 & 11.7 \\
\hline 60.2 & -13.0 & -13.0 & -8.0 & 42.0 & 0.0 & -14.0 & 17.0 & 34.0 & 62.0 & 15.1 & 9.5 \\
\hline 56.1 & -7.0 & -13.0 & -7.0 & 42.0 & 0.0 & -14.0 & 17.0 & 27.0 & 57.2 & 13.1 & 7.6 \\
\hline 51.7 & -4.0 & -13.0 & -6.0 & 42.0 & 0.0 & -14.0 & 17.0 & 23.0 & 55.0 & 12.1 & 6.6 \\
\hline 47.3 & -2.0 & -13.0 & -5.0 & 42.0 & 0.0 & -14.0 & 17.0 & 21.0 & 54.0 & 11.6 & 6.0 \\
\hline 42.8 & -1.0 & -13.0 & -5.0 & 42.0 & 0.0 & -14.0 & 17.0 & 19.0 & 53.2 & 11.2 & 5.5 \\
\hline 38.5 & -1.0 & -13.0 & -5.0 & 42.0 & 0.0 & -14.0 & 17.0 & 18.0 & 52.9 & 11.2 & 5.5 \\
\hline 34.4 & -1.0 & -13.0 & -5.0 & 42.0 & 0.0 & -14.0 & 17.0 & 18.0 & 52.9 & 11.2 & 5.5 \\
\hline 30.5 & -1.0 & -13.0 & -5.0 & 42.0 & 0.0 & -14.0 & 17.0 & 18.0 & 52.9 & 11.2 & 5.6 \\
\hline
\end{tabular}

\section{Discussion}

It is evident from the results presented above that the molecular oxygen dayglows, $\mathrm{O}_{2}\left({ }^{l} \Delta\right)$ and $\mathrm{O}_{2}\left({ }^{l} \Sigma\right)$, may provide very accurate measures of the ozone concentration from the upper stratosphere into the lower thermosphere (below $92 \mathrm{~km}$ ) if several key kinetic and spectroscopic parameters can be determined to accuracies of $5 \%$ to $7 \%$, and if measurements are made with well-calibrated instruments. However, the uncertainties in most rates are far greater than $5 \%$ to $7 \%$. In fact, the total uncertainties presented in the columns labeled RSS in Tables 2 and 3 may be optimistic. For example, at mesospheric temperatures, quenching rates $k_{c}, k_{d}, k_{j}$, and $k_{f}$ are uncertain by $25 \%$ to $40 \%$ [JPL-92], while $\phi_{\mathrm{e}}$ is uncertain by as much as $20 \%$ [Knickelbein et al., 1987]. In addition, a key parameter in the inference of ozone concentration from measurements of $\mathrm{O}_{2}\left({ }^{1} \Delta\right)$ emission is the Einstein A-coefficient for spontaneous emission of the $\mathrm{O}_{2}\left({ }^{1} \Delta\right)$ state, and it is uncertain by nearly a factor of 2 , as shown by Mlynczak and Nesbitt [1995]. Finally, based on the results in the RSS' columns of Tables 2 and 3, it is unlikely that either oxygen airglow feature can provide an accurate (RSS < $15 \%)$ measure of the ozone concentration above $\sim 92 \mathrm{~km}$.

It is important that the kinetic and spectroscopic rates and mechanisms defined in this letter be better determined in the near future. A coordinated and focused laboratory effort is needed to determine the rate constants to the accuracies as described above. These efforts will greatly aid the study of mesospheric ozone through the potential reprocessing of SME data, the analysis of HRDI data, and the interpretation of new measurements from the SABER instrument.

\section{References}

Garcia, R. R., and S. Solomon, A numerical model of the zonally averaged dynamical and chemical structure of the middle atmosphere, J. Geophys. Res., 88, 1379-1400, 1983.
Garcia, R. R., and S. Solomon, The effect of breaking gravity waves on the dynamics and chemical composition of the mesosphere and lower thermosphere, J. Geophys. Res., 90, 3850-3868, 1985.

Harries, J. E.. Stratospheric composition measurements as tests of photochemical theory, J. Aim. Terr. Phys., 44, 591-597, 1982.

JPL. Jet Propulsion Laboratory, Chemical kinetics and photochemical data for use in stratospheric modeling, JPL 92-20, Evaluation 10, 196 pp., NASA Panel for Data Evaluation, Jet Propulsion Laboratory. Pasadena, Calif., 1992

Knickelbein, M. B., K. L. Marsh, O. E. Ulrich, and G. E. Busch, Energy transfer kinetics of singlet molecular oxygen: The deactivation channel for $\mathrm{O}_{2}\left(\mathrm{~b}^{1} \Sigma_{\mathrm{g}}\right), J$. Chem. Phys., 87, 2392-2393, 1987.

Mlynczak, M. G., and D. J. Nesbitt, The Einstein coefficient for spontaneous emission of the $\mathrm{O}_{2}\left(\mathrm{a}^{1} \Delta \mathrm{g}\right)$ state, Geophys. Res. Lett., 22 , 1995, in press.

Mlynczak, M. G., S. Solomon, and D. S. Zaras, An updated model for $\mathrm{O}_{2}\left(\mathrm{a}^{\mathrm{l}} \Delta \mathrm{g}\right)$ concentrations in the mesosphere and lower thermosphere and implications for remote sensing of ozone at $1.27 \mu \mathrm{m}, J$. Geophys. Res., 98, 18,639-18,648, 1993.

Russell, J. M. III, M. G. Mlynczak, and L.L. Gordley, An overview of the SABER experiment for the TIMED Mission, SPIE Proceedings 2266 Optical Spectroscopic Techniques and Instrumentation for Atmospheric and Space Research, Jinxue Wang and Paul B. Hays, Eds., 406-414, 1994.

Thomas, R. J., C. A. Barth, D. W. Rusch, and R. W. Sanders, Solar Mesosphere Explorer near-infrared spectrometer: Measurements of $1.27-\mu \mathrm{m}$ radiances and the inference of mesospheric ozone, $J$. Geophys. Res., 89, 9569-9580, 1984.

Yee, J. H., D. E. Anderson, C. I. Meng, R. DeMajistre, W. Sharp, W. Skinner. and P. B. Hays. Retrieval of $\left.O^{1} \mathrm{D}\right)$ and $\mathrm{O}_{3}$ number densities from measurements of the $\mathrm{O}_{2}\left({ }^{1} \Sigma\right)$ atmospheric band, Trans. Amer. Geophys. Union. 74, 473, 1993.

Martin G. Mlynczak, NASA Langley Research Center, Mail Stop 401B, Hampton, VA 23681-0001

Daphne S. Olander. NOAA Science Center, E/RA21, 5200 Auth Road, Room 601, Washington, DC 20233.

(Received January 20, 1995: revised March 17, 1995; accepted March 28, 1995.) 